\title{
ANALISIS KEBERLANJUTAN SUMBERDAYA PERIKANAN DENGAN \\ MENGGUNAKAN JARING PERANGKAP (TRAP NET) DI WILAYAH PESISIR PANTAI KABUPATEN PANGKEP
}

\author{
Analysis Of Sustainability Of Fisheries Resources Using The Trap Network (Trap Net) \\ In The Coastal Coastal Area Of Pangkep District
}

Oleh:

\author{
Risnawati $^{1}$, Syahrul $^{2}$ dan Ihsan $^{2}$ \\ 1) Dinas Perikanan Kabupaten Pangkep Sulsel \\ 2) Program Studi Ilmu Kelautan, FPIK UMI \\ 3) Program Studi Pemanfaatan Sumberdaya Perikanan FPIK UMI \\ Korespondensi:Risnawati.B@gmail.com
}

Diterima: tanggal 2 Januari 2019; Disetujui 31 April 2019

\begin{abstract}
Research of the sustainability analysis of fisheries resources by using trap net in the coastal of Pangkep Regency was conducted on August to October 2018 in the coastal zone of pangkep Regency. This research aims to 1) Analyze the location of trap net fishing areas, (2) Analyze environmental friendliness of trap net, (3) Analyze the sustainability of fish resources by using trap net in the coastal areas of Pangkep district. The method used was case study by following fishing operations using trap net directly. Analyzed of the determination of the trap net installation location was used by geographic information systems (GIS), analyzed the selectivity of fishing gear used the formula based on the provisions of FAO (1995), and analyzed the sustainability of fish resources used Rapfish analysis. Results of the research showed that fishing ground of using trap net covers the coastal areas of Pangkep Regency, there were four locations that have been determined based on analysis, which were Districts of Bungoro, Labakkang, Ma'rang, and Segeri. Trap net included in fishing gear that was not environmentally friendly, so it does not support the sustainability of fisheries resources. Utilization of fishery resources by using a trap net in the coastal areas of Pangkep Regency is less sustainable.
\end{abstract}

Keywords: Selectivity, Sustainability, Trap Net, Rapfish

\begin{abstract}
ABSTRAK
Penelitian ini bertujuan (1) mengalisis lokasi daerah penangkapan trap net, (2) menganalisis keramahan lingkungan alat tangkap trap net, (3) menganalisis keberlanjutan sumberdaya ikan dengan menggunakan trap net di wilayah pesisir kabupaten pangkep. Penelitian ini dilaksanakan pada Bulan Agustus-Oktober 2018 di wilayah pesisir pantai Kabupaten Pangkep, di 4 Kecamatan yaitu Bungoro, Labakkang, Ma'rang, dan Segeri. Metode yang digunakan adalah studi kasus dengan mengikuti secara langsung operasi penangkapan ikan menggunakan trap net. Analisis penentuan lokasi pemasangan trap net digunakan system informasi geografis (SIG), manganalisis selektivitas alat tangkap digunakan rumus ketetapan keramahan alat tangkap berdasarkan ketentuan FAO (1995), dan untuk menganalisis keberlanjutan sumberdaya ikan digunakan analisis Rapfish. Hasil penelitian menunjukkan DPI dengan menggunakan trap net mencakup wilayah pesisir Kabupaten Pangkep terdapat empat lokasi yang telah ditetapkan berdasarkan analisis yaitu di Kecamatan Bungoro, Labakkang, Ma'rang, dan Segeri. Trap net termasuk alat tangkap yang tidak ramah lingkungan, sehingga tidak mendukung keberlanjutan sumberdaya perikanan. Pemanfaatan sumberdaya perikanan dengan menggunakan jaring perangkap (trap net) di wilayah pesisir pantai Kabupaten Pangkep kurang berkelanjutan.
\end{abstract}

Kata kunci : Selektivitas, Keberlanjutan, Jaring Perangkap, Rapfish 


\section{PENDAHULUAN}

Kabupaten Pangkajene dan

Kepulauan (Pangkep) adalah salah satu kabupaten di Provinsi Sulawesi Selatan yang memiliki potensi kelautan dan perikanan yang tinggi. Sesuai dengan namanya yang melekat kata kepulauan, Kabupaten Pangkep memiliki pulaupulau kecil yang sangat banyak, yaitu 115 pulau yang tersebar pada gugusan kepulauan Spermonde di perairan Selat Makassar yang secara administratif memiliki luas $12.362,73 \mathrm{~km} 2$ yang terdiri dari 898,29 $\mathrm{km} 2$ luas daratan dan $11.564,44 \mathrm{~km} 2$ luas perairan laut. Formasi wilayah ini membentuk garis pantai di daratan utama sepanjang 42,57 $\mathrm{km}$ dan garis pantai rangkaian kepulauannya sepanjang $63,57 \mathrm{~km}$ (Dishubkominfo, 2013).

Faktor yang mendasari ikan melakukan perpindahan ontogenetik habitat adalah untuk meningkatkan pertumbuhan dan mengurangi mortalitas akibat tekanan predator serta untuk proses reproduksi. predasi dapat mengurangi tingkat kemampuan suatu individu dalam mencari makan dan selanjutnya dapat mengurangi tingkat pertumbuhan, sehingga ikan akan berpindah ke habitat yang memungkinkan untuk memperoleh sumber makanan dan berlindung dari serangan predator.

Untuk mengelola sumberdaya di wilayah pesisir maka, beberapa Alat tangkap dan teknik penangkapan ikan di Indonesia digunakan, baik masih bersifat tradisional maupun modern dioperasikan oleh nelayan. Dilihat dari prinsip penangkapan ikan di Indonesia para nelayan lebih memanfaatkan sifatsifat yang dimiliki ikan dan lingkungannya. Salah satu alat tangkap yang digunakan nelayan pesisir Kabupaten Pangkep adalah trap net atau nama lokalnya yaitu Tiku. Masyarakat memanfaatkan ruaya ikan dalam proses penangkapannya. Jaring Perangkap (trap net) termasuk dalam alat tangkap perangkap yang sangat tergantung pola sirkulasi air (arus) dan pasang surut. Trap net adalah perangkap pasang surut yang merupakan ciri khas alat penangkapan yang terdapat di sebagian pesisir Kabupaten Pangkep.

Daerah penangkapan ikan menjadi penting diketahui agar nelayan mudah menggunakan peralatan 
penangkapan ikan. Umumnya perairan pantai yang bisa menjadi daerah penangkapan ikan memilki kaitan dengan kelimpahan makanan untuk ikan. Selain itu juga harus memperhatikan tempat tersebut apakah memilki arus yang menghanyutkan dan perbedaan pasang surut yang besar. Pada tempat tersebut, nelayan perlu memperhatikan untuk pengoperasian alat tangkap Jaring (trap net).

Habitat mangrove merupakan daerah asuhan bagi berbagai jenis ikan dan fauna laut (Lugendo et al. 2006). Jenis-jenis ikan yang ditemukan di kawasan mangrove diantaranya dari family Carangidae, Clupeidae, Cynoglossidae, Gobidae, Latidae, Lutjanidae, Mullidae, Mugillidae, Scombridae, Serranidae, Siganidae, Terraponidae, Trichiuridae (Genisa 2006), serta masih banyak jenis lainnya yang juga bernilai cukup penting baik dari segi ekonomis maupun ekologis. Selain keragaman potensi yang dimiliki, ekosistem ini juga mempunyai fungsi yang bermacam-macam, diantaranya sebagai daerah asuhan bagi pasca larva jenis-jenis tertentu dari ikan, udang dan bangsa crustacea lainnya. Sistem perakarannya yang khas menjadikan ekosistem mangrove sebagai tempat berlindung dan habitat yang baik bagi berbagai jenis biota air. Sehubungan dengan hal tersebut pengelolaan trap net dengan ekosistem mangrove menjadi penting diperhatikan, untuk meningkatkan produksi dan produktifitas hasil tangkapan trap net.

Tujuan dari penelitian ini adalah untuk menganalisis lokasi daerah pemasangan jaring perangkap (trap net), menganalisis keramahan lingkungan, serta menganalisis keberlanjutan sumberdaya perikanan dengan menggunakan trap net di wilayah pesisir Pantai Kabupaten Pangkep.

\section{METODE PENELITIAN}

Penelitian ini dilaksanakan di wilayah Pesisir Pantai Kabupaten Pangkajene dan Kepulauan di Desa Bulu Cindea Kecamatan Bungoro, Desa Bonto Manai Kecamatan Labakkang, Kelurahan Talaka Kecamatan Ma'rang, dan Kelurahan Bone Kecamatan Segeri. Penelitian ini berlangsung mulai Agustus sampai Oktober 2018. 


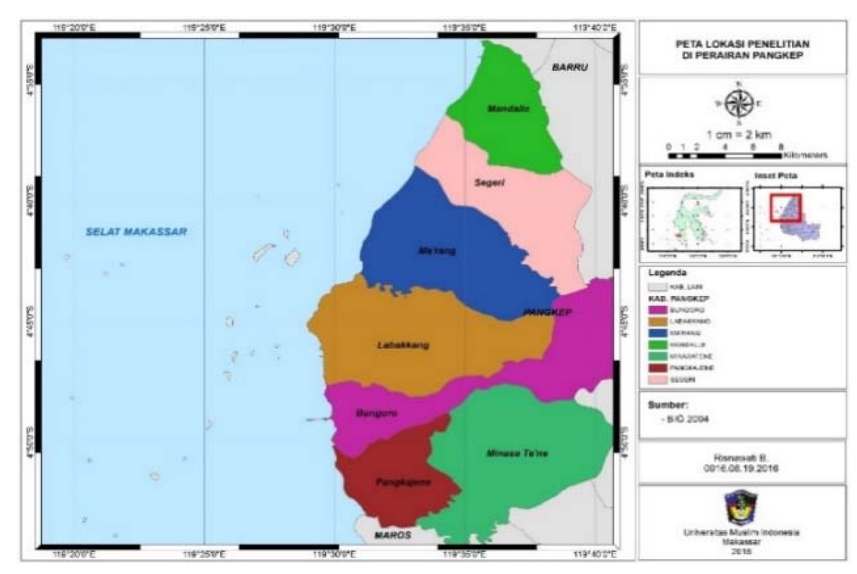

Gambar 1. Peta Lokasi Penelitian

Alat yang digunakan pada penelitian. Adapun alat yang digunakan penelitian ini merupakan instrumen serta kegunaannya dapat dilihat pada yang menunjang pengambilan data Tabel 1.

Tabel 1. Alat yang digunakan dan kegunaannya.

\begin{tabular}{|c|c|c|}
\hline No. & Alat & Kegunaan \\
\hline 1 & $\begin{array}{l}\text { Global Positioning } \\
\text { System(GPS) }\end{array}$ & $\begin{array}{l}\text { Menentukanposisi daerah pemasangan alat } \\
\text { tangkap }\end{array}$ \\
\hline $\begin{array}{l}2 \\
3 \\
4 \\
5\end{array}$ & $\begin{array}{l}\text { Termometerdigital } \\
\text { Timbangandigital } \\
\text { Kameradigital } \\
\text { Buku Harian Kapal }\end{array}$ & $\begin{array}{l}\text { kur suhupermukaanlaut } \\
\text { kur beratikanhasil tangkapan } \\
\text { kumentasikanpenelitian } \\
\text { atdataproduksidan daerah penangkapan }\end{array}$ \\
\hline $\begin{array}{l}\text { dalam } \\
\text { primer } \\
\text { bersun } \\
\text { mengg } \\
\text { dipero } \\
\text { pengar } \\
\text { dengar } \\
\text { peman }\end{array}$ & $\begin{array}{l}\text { Data yang akan dikumpulkan } \\
\text { penelitian ini terdiri dari data } \\
\text { dan sekunder. Data primer } \\
\text { ber dari nelayan tangkap yang } \\
\text { unakan alat tangkap trap net yang } \\
\text { eh dengan melakukan } \\
\text { aatan langsung di lapangan dan } \\
\text { wawancara langsung dengan } \\
\text { gku kebijakan dan masyarakat }\end{array}$ & $\begin{array}{l}\text { setempat. Untuk melengkapi data hasil } \\
\text { wawancara digunakan kuisioner yang } \\
\text { bertujuan untuk mengetahui presepsi } \\
\text { masyarakat dalam keberlanjutan } \\
\text { sumberdaya perikanan jaring perangkap } \\
\text { (trap net). } \\
\text { Data sekunder diperoleh dari } \\
\text { instansi terkait yaitu Dinas Perikanan } \\
\text { Kabupaten Pangkajene dan Kepulauan } \\
\text { selain itu juga ada data yang diperoleh }\end{array}$ \\
\hline
\end{tabular}


langsung dengan sistem penginderaan jauh yang di ambil melaui Citra Satelit Landsat .

Penentuan Responden Dalam penelitian ini subjeknya adalah nelayan jaring perangkap (trap net) terpilih secara acak yang ada di pesisir Kabupaten Pangkajene dan Kepulauan. Teknik penentuan sampel yang digunakan adalah purposive sampling yaitu cara pengambilan sampel atau penentuan responden dengan menetapkan ciri yang sesuai dengan tujuan (Lynch,1974) dan proportional sampling yaitu pengambilan sampel yang memperhatikan pertimbangan unsur-unsur atau kategori dalam populasi penelitian (Rubbin dan Luck,1987), dimana penelitian ini tidak dilakukan pada seluruh populasi, tapi terfokus pada target.

Metode yang digunakan dalam penelitian ini adalah metode survei dengan penentukan daerah potensial pemasangan trap net menggunakan ArcGIS 10.2. selanjutan analisis keramahan lingkungan berdasarkan kriteria utama penilaian terhadap keramahan lingkungan berdasarkan ketentuan FAO (1995) dengan 9 kriteria. penentuan daerah lokasi penangkapan alat analisis teknik Rapfish. Teknik Rapfish (Rapid Appraissal for Fisheries) dikembangkan oleh University of British Columbia Canada, yang merupakan analisis untuk mengevaluasi sustainability atau keberlanjutandari sumberdaya perikanan secara multidisipliner. Rapfish didasarkan pada teknik ordinasi yaitu menempatkan sesuatu nilai (skor) pada atribut yang terukur dengan menggunakan MultiDimensional Scaling (MDS). Aspek dalam Rapfish menyangkut aspek dari ekologi, ekonomi, dan teknologi.

Tahapan awal dalam analisis Rapfish adalah penentuan dimensi dan atribut keberlanjutan dari suatu sumberdaya yang akan dianalisis. Prosedur analisis Rapfish dapat dilihat pada Gambar 2 bagan dibawah ini : 


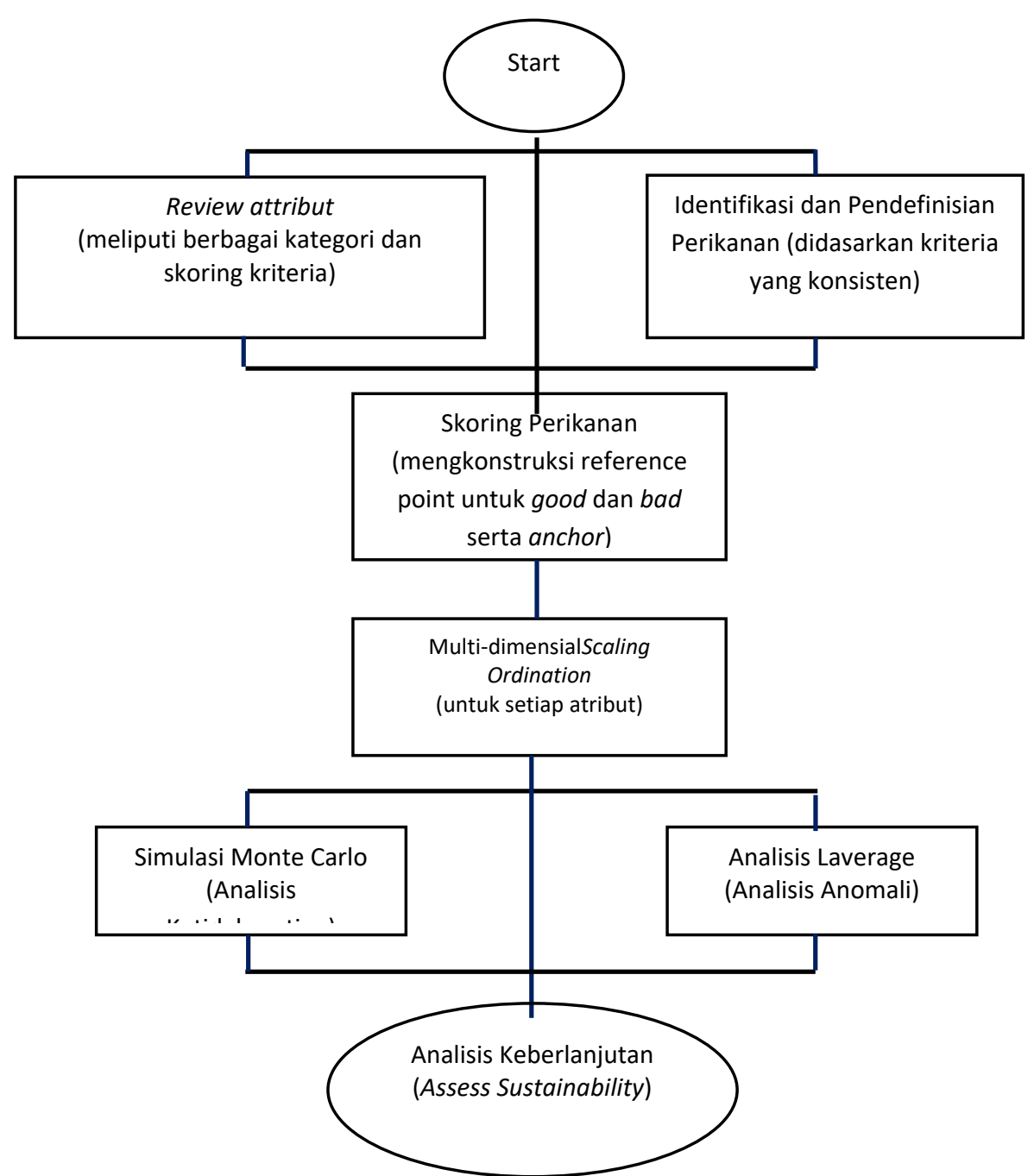

Gambar 2. Bagan Prosedur Analisis Rapfish

\section{HASIL DAN PEMBAHASAN}

\section{Lokasi Daerah Penangkapan Jaring Perangkap (Trap net)}

Jumlah spesies yang tertangkap menggunakan jaring perangkap (trap net) di wilayah pesisir Kabupaten Pangkajene dan Kepulauan yang memiliki nilai jual khususnya di empat
Kecamatan yaitu Kecamatan Bungoro, Kecamatan Labakkang, Kecamatan Ma'rang, dan Kecamatan Segeri. Berdasarkan hasil penelitian menunjukkan komposisi jenis hasil tangkapan (trap net) mencakup 22 jenis yang mendominasi oleh beberapa jenis akan dapat dilihat pada Tabel 2 di bawah ini: 
Tabel 2. Jumlah Jenis Hasil tangkapan yang tertangkap selama penelitian Bulan Agustus - September

\begin{tabular}{lll}
\hline No & \multicolumn{1}{c}{ Nama Indonesia } & \multicolumn{1}{c}{ Nama Latin } \\
\hline 1 & Kakap Putih & Lates calcarifer \\
2 & Kakap Hitam & Lutjanus buccanella \\
3 & Kerapu Lumpur & Epinephelus/fuscoguttarus \\
4 & Gulamah/Tigawajah & Nibea albiflora \\
5 & Titang/Bidang & Scatophagus sp. A \\
6 & Tembang & Sardinella branchysoma \\
7 & Kurau / Manangi & Eleutheronema / tetradactylum (Shaw, 1804) \\
8 & Ikan Lidah & Cynoglossus spp \\
9 & Nila & Oerochromis niloticus \\
10 & Baronang Lingkis & Siganus canaliculatus \\
11 & Belanak & Valamugil seheli \\
12 & Bandeng & Chanos chanos \\
13 & Kwee & Caranx tille \\
14 & Rejung & Sillago sihama (Forsskal,1775) \\
15 & Udang Jerbung/Udang Putih & Penaeus merguiensis(de Man, 1988) \\
16 & Sembilang & Euristhmus microceps \\
17 & Kapas - Kapas & Gerres erythrourus \\
18 & Kepiting Bakau & Scylla serrata (Forsskai 1755) \\
19 & Kerong-kerong & Terapon theraps (cuvier 1928) \\
20 & Julung-Julung & Hemirhamphus spp \\
21 & Udang windu & Penaeus monodon(Fabricius, 1798) \\
22 & Kapas Besar & Gerres filamentosus \\
\hline
\end{tabular}

Tabel 3. Titik Koordinat Penangkapan Trap net dan Luasan

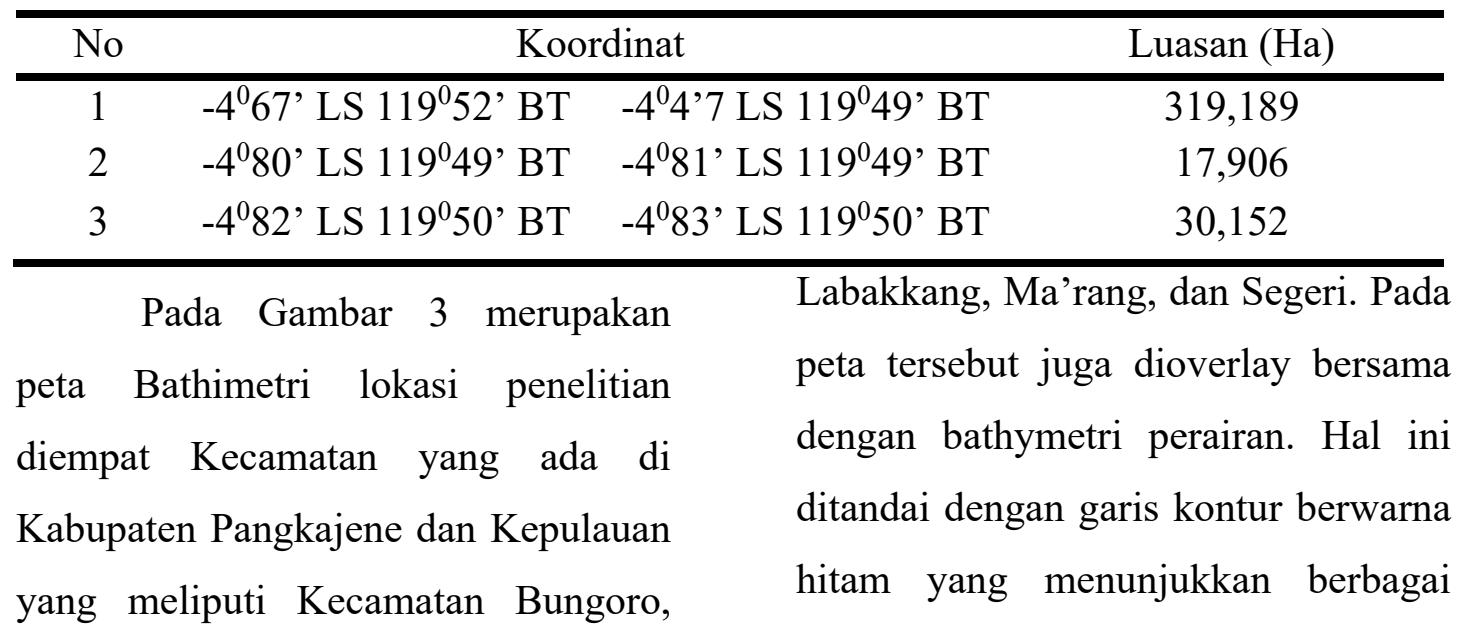


variasi kedalaman mulai dari 0 sampai -50 meter. Berdasarkan luas wilayah yang diperoleh pada Tabel 3 dapat mencakup banyak alat tangkap, akan tetapi hal penting yang perlu diperhatikan adalah wilayah pesisir merupakan alur pelayaran keluar masuk dari pangkalan pendaratan oleh karena itu perlu adanya aturan bahwa setiap Trap net tidak boleh dioperasikan pada daerah di mana merupakan alur pelayaran nelayan dari dan ke pada lokasi daerah penangkapan ikan (fishing ground).

$\begin{array}{lcr}\text { Salah } & \text { satu langkah } & \text { yang } \\ \text { dilakukan } & \text { pemerintah } & \text { dalam } \\ \text { menghindari } & \text { terjadinya } & \text { konfllik } \\ \text { pemanfaatan } & \text { adalah } & \text { dengan }\end{array}$

mengendalikan

perkembangan kegiatan penangkangkapan ikan melalui penerapan zonasi Jalur Penangkapan Ikan di laut, berdasarkan Kepmentan No. 392 Tahun 1999 yang isinya antara lain mengatur pembagian daerah penangkapan ikan dan penentuan jenis, ukuran kapal, dan alat penangkapan ikan yang dilarang dan diperbolehkan penggunaannya. Zonasi merupakan suatu bentuk rekayasa teknik pemanfaatan ruang melalui penetapan batas-batas fungsional sesuai dengan potensi sumberdaya dan daya dukung serta proses-proses ekologis yang berlangsung sebagai satu kesatuan dalam ekosistem pesisir (Supriharyono, 2000).

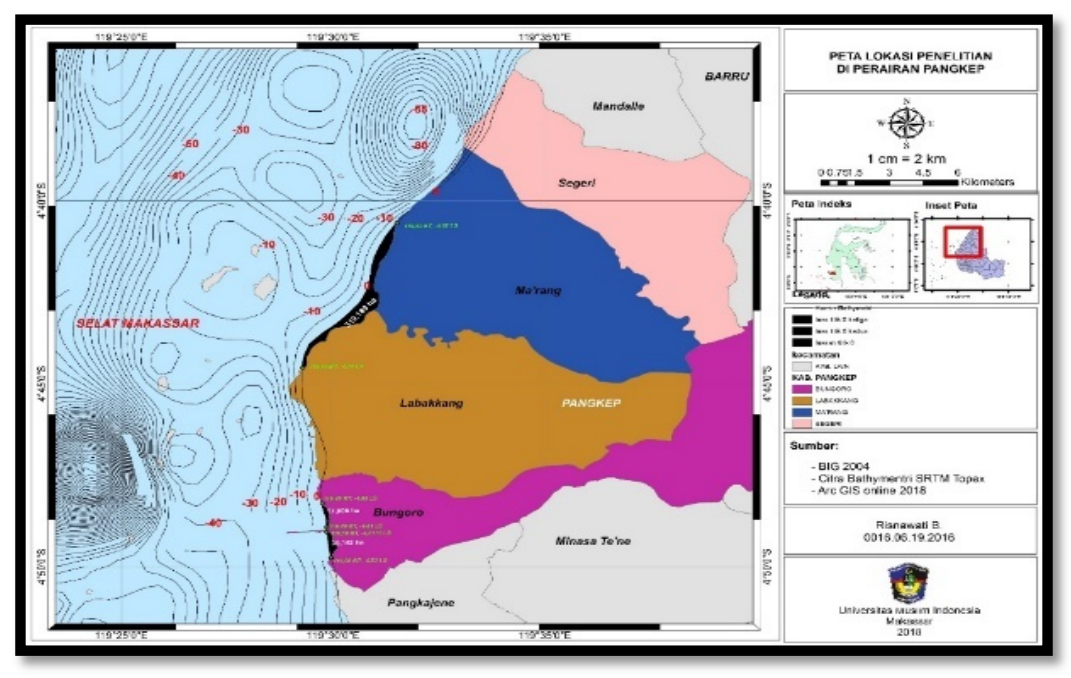

Gambar 3. Peta Batimetri Daerah Pemasangan alat tangkap (trap net) 
Tingkat Keramahan Lingkungan dengan Menggunakan Jaring Perangkap (Trap net)

Dalam upaya mengetahui tingkat keramahan lingkungan alat tangkap yang digunakan oleh nelayan di wilayah pesisir Kabupaten Pangkajene dan Kepulauan maka peneliti mengambil seluruh responden nelayan jaring perangkap (trap net) yang ada pada empat kecamatan tersebut. Di mana jumlah responden untuk keseluruhan adalah 10 orang. Selain itu peneliti juga mengikuti pengoperasian alat sebanyak tiga orang untuk melihat secara langsung metode pengoperasian alat dan melihat langsung jenis hasil tangkapan yang tertangkap selama Bulan September dan Oktober Tahun 2018.

$$
\text { Pada tabel keramahan lingkungan }
$$
alat tangkap tersebut pengumpulan data secara manual dengan menggunakan teknik deskriptif analitik. Sehingga dapat diperoleh hasil keramahan lingkungan alat tangkap trap net. Dapat dilihat pada Tabel 4 di bawah ini :

Tabel 4. Kriteria Teknologi Penangkapan Jaring Perangkap (Trap net) yang Ramah Lingkungan Menurut FAO (1995)

\begin{tabular}{|c|c|c|c|c|c|c|c|c|c|c|c|c|}
\hline \multirow{2}{*}{ No } & \multirow{2}{*}{$\begin{array}{l}\text { Kriteria alat tangkap ramah } \\
\text { lingkungan FAO (1995) }\end{array}$} & \multicolumn{10}{|c|}{ Responden } & \multirow[t]{2}{*}{$\begin{array}{r}\text { Jumlah } \\
\text { Bobot }\end{array}$} \\
\hline & & 1 & 2 & 3 & 4 & 5 & 6 & 7 & 8 & 9 & 10 & \\
\hline 1 & mempunyai selektivitas tinggi & 1 & 1 & 1 & 1 & 1 & 1 & 1 & 1 & 1 & 1 & 10 \\
\hline 2 & Tidak merusak lingkungan & 1 & 1 & 1 & 1 & 1 & 1 & 1 & 1 & 1 & 1 & 10 \\
\hline 3 & $\begin{array}{l}\text { Menghasilkan ikan berkualitas } \\
\text { tinggi }\end{array}$ & 3 & 3 & 3 & 4 & 3 & 3 & 3 & 4 & 3 & 3 & 32 \\
\hline 4 & Tidak membahayakan nelayan & 3 & 3 & 3 & 3 & 3 & 3 & 3 & 3 & 3 & 3 & 30 \\
\hline 5 & $\begin{array}{l}\text { Produksi tidak membahayakan } \\
\text { konsumen }\end{array}$ & 4 & 4 & 4 & 3 & 4 & 4 & 3 & 4 & 4 & 4 & 38 \\
\hline 6 & $\begin{array}{l}\text { Hasil tangkapan yang terbuang } \\
\text { minimum }\end{array}$ & 1 & 1 & 1 & 1 & 1 & 1 & 1 & 1 & 1 & 1 & 10 \\
\hline 7 & $\begin{array}{l}\text { Alat tangkap yang digunakan } \\
\text { harus memberikan dampak } \\
\text { minimum terhadap keanekaan } \\
\text { SBD hayati (biodiversity) }\end{array}$ & 1 & 1 & 1 & 1 & 1 & 1 & 1 & 1 & 1 & 1 & 10 \\
\hline 8 & $\begin{array}{l}\text { Tidak membahayakan ikan } \\
\text { ikan yang dilindungi }\end{array}$ & 1 & 1 & 1 & 1 & 1 & 1 & 1 & 2 & 1 & 2 & 12 \\
\hline 9 & diterima secara sosial & $\begin{array}{c}2 \\
\mathrm{AL}\end{array}$ & 2 & 2 & 2 & 3 & 3 & 2 & 2 & 3 & 2 & $\begin{array}{c}23 \\
175\end{array}$ \\
\hline
\end{tabular}


Keberlanjutan Sumberdaya Ikan dengan menggunakan Jaring Perangkap (Trap net)

Analisis keberlanjutan sumberdaya ikan di wilayah Pesisr Pantai Kabupaten Pangkep didasarkan pada beberapa aspek yang erat kaitannya dalam pemanfaatan sumberdaya perikanan. Dalam analisis keberlanjutan ini digunakan teknik Rapfish yakni analisis dengan metode Multi Dimensional Scalling (MDS) dengan tiga dimensi yaitu: ekologi, ekonomi, dan teknologi.

\section{Dimensi Ekologi}

Dimensi ekologi terdiri dari 4 (enam) atribut yaitu: (1) tingkat pemanfaatan sumberdaya ikan; (2) ukuran tangkapan; (3) jumlah jenis tangkapan; (4) kondisi hutan mangrove. Analisis ordinasi menunjukkan bahwa keberlanjutan secara ekologi terletak antara bad dan good. Analisis ordinasi dengan iterasi sebanyak 3 (tiga) kali, menghasilkan korelasi kuadrat (R2) sebesar 92,41 \% dan nilai stress (S) sebesar $17,5 \%$. Nilai ini menunjukkan bahwa seberapa besar hasil analisis ini dapat dipercaya. Semakin mendekati 100\% nilai dari korelasi kuadrat (R2) maka semakin dipercaya bahwa keseluruhan atribut tersebut berhubungan dengan dimensi ekologi.

Dalam analisis Multi Dimensional Scalling (MDS) nilai stress yang baik sebesar kurang dari 25\% (Fauzi dan Anna, 2005). Dengan demikian analisis dimensi ekologi dalam penelitian ini menunjukkan goodness off it karena nilai stress yang diperoleh sebesar 17,5 \% yang lebih kecil dari 25\%. Penentuan keberlanjutan dari hasil analisis ordinasi dapat dikelompokkan menjadi empat kategori tingkat keberlanjutan yang berbeda yaitu: 0 - 25 adalah buruk, $26-$ 50 adalah kurang, 51 - 75 adalah cukup dan 76 - 100 adalah baik. Hasil ordinasi dengan nilai 43,67 menunjukkan bahwa dimensi ekologi termasuk kategori kurang dalam mendukung keberlanjutan pemanfaatan sumberdaya ikan di wilayah Pesisir Pantai Kabupaten Pangkep.

Nilai leverage masing-masing atribut adalah sebagai berikut : (1) tingkat pemanfaatan sumberdaya ikan senilai 5,0 ; (2) ukuran tangkapan 4,17 ; (3) Keragaman tangkapan 8,04; (4) kondisi hutan mangrove 0,97. Atribut jumlah tingkat keragaman hasil 
tangkapan dan tingkat pemanfaatan menghasilkan leverage masing-masing sebesar 8,01 dan 5,08 merupakan dua nilai terbesar dari atribut yang dianalisis. Hal ini berarti bahwa kedua atribut tersebut merupakan indikator dari keberlanjutan pemanfaatan sumberdaya ikan di Wilayah Pesisir Pantai Kabupaten Pangkep yang perlu mendapat perhatian.

\section{Dimensi Ekonomi}

Dimensi ekonomi terdiri dari 4 (empat) atribut yaitu : (1) keuntungan hasil tangkapan; (2) pasar; (3) pendapatan lain; (4) subsidi. Analisis ordinasi dengan iterasi sebanyak 3 (tiga) kali, menghasilkan korelasi kuadrat (R2) sebesar 91\% dan nilai stress (S) sebesar 16,16\%. Nilai ini menunjukkan bahwa seberapa besar hasil analisis ini dapat dipercaya. Semakin mendekati 100\% nilai dari korelasi kuadrat (R2) maka semakin dipercaya bahwa keseluruhan atribut tersebut berhubungan dengan dimensi ekonomi.

Dalam analisis Multi Dimensional Scalling (MDS) nilai stress yang baik sebesar kurang dari 25\% (Fauzi dan Anna, 2005). Dengan demikian analisis dimensi ekonomi dalam penelitian ini menunjukkan goodness of fit karena nilai stress yang diperoleh sebesar $16,16 \%$ yang lebih kecil dari 25\%. Penentuan keberlanjutan dari hasil analisis ordinasi dapat dikelompokkan menjadi empat kategori tingkat keberlanjutan yang berbeda yaitu : 0 25 adalah buruk, 26 - 50 adalah kurang, 51 - 75 adalah cukup dan $76-100$ adalah baik. Hasil ordinasi dengan nilai 65,05 menunjukkan bahwa dimensi ekonomi termasuk kategori cukup dalam mendukung keberlanjutan pemanfaatan sumberdaya ikan di Pesisir Pantai Kabupaten Pangkajene dan Kepulauan.

Nilai leverage masing-masing atribut adalah sebagai berikut : (1) keuntungan hasil tangkapan senilai 4,42; (2) pasar 22,75; (3) pendapatan lain 15,08; dan (4) Subsidi dengan nilai 11,83.Hasil analisis leverage menunjukkan bahwa atribut pasar memiliki nilai tertinggi dibandingkan dengan atribut lainnya yakni sebesar 22,75. Atribut pasar menunjukkan bahwa pasar memerlukan perhatian untuk meningkatkan pendapatan ekonomi. 


\section{Dimensi Teknologi}

Dimensi teknologi terdiri dari 4 (empat) atribut yaitu : (1) lama trip; (2) sifat alat tangkap; (3) selektivitas alat tangkap; (4) pengaruh negative alat tangkap. Analisis ordinasi menunjukkan bahwa keberlanjutan secara teknologi terletak antara bad dan good. Analisis ordinasi dengan iterasi sebanyak 3 (tiga) kali, menghasilkan korelasi kuadrat (R2) sebesar $93.26 \%$ dan nilai stress (S) sebesar $16,28 \%$. Nilai ini menunjukkan bahwa seberapa besar hasil analisis ini dapat dipercaya. Semakin mendekati $100 \%$ nilai dari korelasi kuadrat (R2) maka semakin dipercaya bahwa keseluruhan atribut tersebut berhubungan dengan dimensi teknologi.

Dalam analisis Multi Dimensional Scalling (MDS) nilai stress yang baik sebesar kurang dari 25\% (Fauzi dan Anna, 2005). Dengan demikian analisis dimensi teknologi dalam penelitian ini menunjukkan goodness of fit karena nilai stress yang diperoleh sebesar $16,28 \%$ yang lebih kecil dari $25 \%$. Penentuan keberlanjutan dari hasil analisis ordinasi dapat dikelompokkan menjadi empat kategori tingkat keberlanjutan yang berbeda yaitu : 0 -
25 adalah buruk, 26 - 50 adalah kurang, 51 - 75 adalah cukup dan $76-100$ adalah baik. Hasil ordinasi dengan nilai 25,16 menunjukkan bahwa dimensi teknologi termasuk kategori buruk dalam mendukung keberlanjutan pemanfaatan sumberdaya perikanan di Pesisir Pantai Kabupaten Pangkajene dan Kepulauan.

Nilai leverage masing-masing atribut adalah sebagai berikut : (1) lama penangkapan senilai 8,49 ; (2) sifat alat tangkap 8,40; (3) selektivitas alat tangkap 8,78; dan (4) pengaruh negative alat tangkap senilai 3,01. Hasil analisis leverage dimensi teknologi menunjukkan bahwa atribut teknologi selektivitas alat tangkap, nilai leverage tertinggi yaitu sebesar 8,78. Atribut tersebut menjadi perhatian karena pada umumnya teknologi pemanfaatan yang digunakan oleh nelayan trap net di Pesisir Pantai Kabupaten Pangkajene dan Kepulauan termasuk dalam kategori buruk, hal ini dibuktikan dengan jumlah dan jenis teknologi yang digunakan tidak memadai, karena tidak adanya berbagai jenis alat tangkap, sarana penangkapan, dan alat komunikasi dalam melakukan distribusi dan 
penjualan ikan hasil tangkapan. Secara ringkas tingkat keberlanjutan pemanfaatan sumberdaya perikanan di
Pangkajene dan Kepulauan berdasarkan dimensi dan aktivitas masyarakat disajikan pada Tabel 5 di bawah ini.

\section{Wilayah Pesisir Pantai Kabupaten}

Tabel 5. Tingkat Keberlanjutan Pemanfaatan Sumberdaya Ikan di Wilayah Pesisir Pantai Kabupaten Pangkep

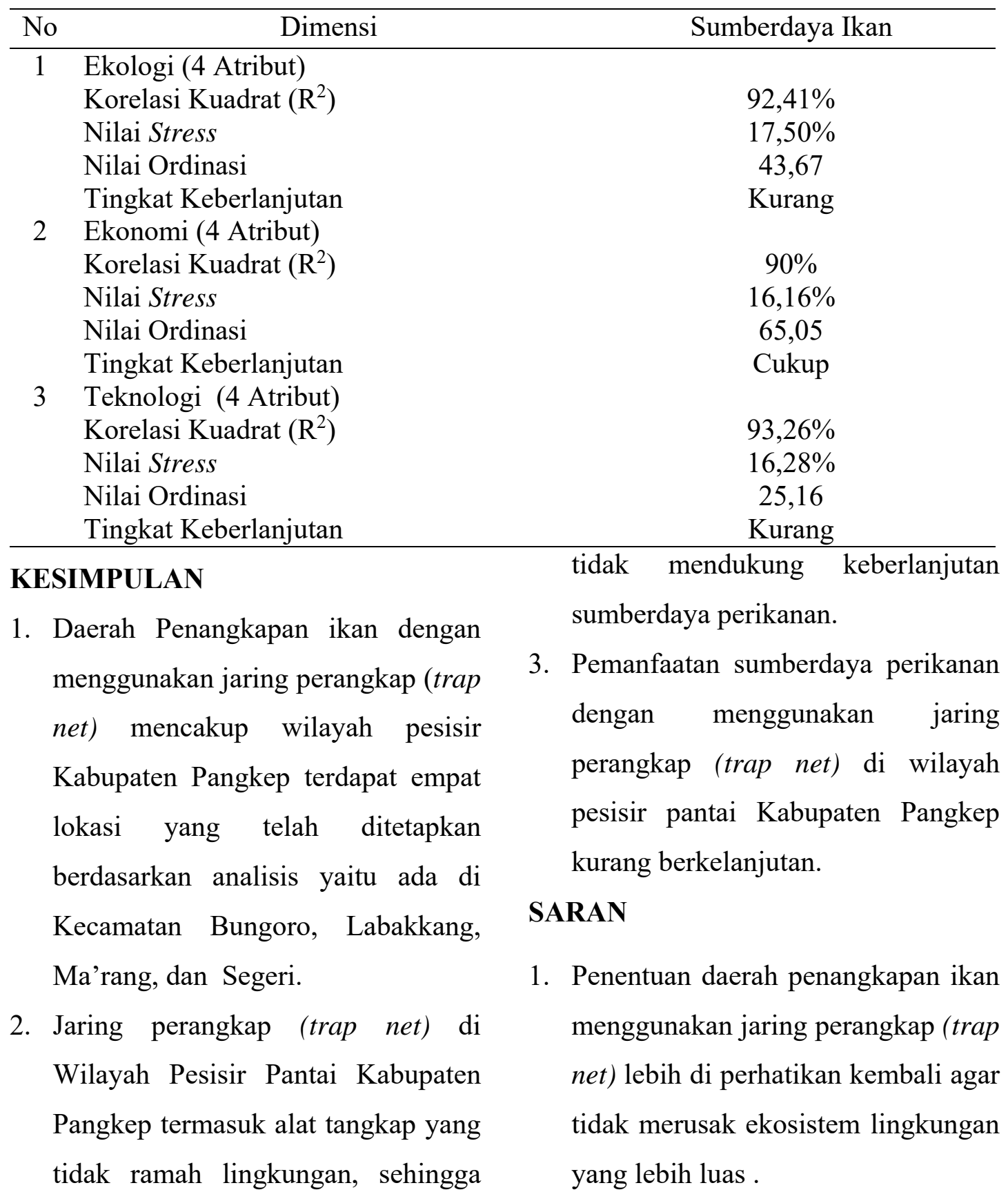


2. Untuk meningkatkan keberlanjutannya maka strategi yang dilakukan adalah mencari informasi pemasaran yang tinggi, melakukan pengolahan hasil tangkapan sebelum di pasarkan, serta perlu adanya modifikasi mesh size trap net, yang lebih besar sehingga lebih efektif dalam penangkapan.

3. Perhatian yang lebih untuk Stakeholder dalam hal ini pemerintah baik pusat, provinsi, maupun daerah pada aspek sosial budaya, teknologi, kelembagaan, dan hukum untuk status keberlanjutan ikan di wilayah pesisir. Strategi yang perlu dilakukan adalah penguatan pelarangan menggunakan alat tangkap yang tidak selektif.

\section{UCAPAN TERIMA KASIH}

Tulisan ini merupakan bagian dari penelitian dasar unggulan perguruan tinggi dan penulis mengucapkan terima kasih kepada Pemerintah Kabupaten Pangkep yang telah memberikan izin untuk melanjutkan studi.

\section{DAFTAR PUSTAKA}

FAO. 1995. Code of Conduct for Responsible Fisheries. FAO Fisheries Department. 24p.

Fauzi, A. dan S. Anna. 2005. Pemodelan Sumber Daya Perikanan dan Kelautan: untuk Analisis Kebijakan. PT. Gramedia Pustaka Utama, Jakarta.

Genisa AS. 2006. Keanekaragaman fauna ikan diperairan mangrove Sungai Mahakam, Kalimantan Timur. Oseanologi dan Limnologi di Indonesia. 41:3953.

Luck, D.J., and R.S. Rubin. 1987. Marketing Research. Seventh edition. Prentice-Hall Inc. New Jersey.

Lugendo BR, Nagelkerken I, Mgaya Y.D. 2006. The importance of mangroves, mud and sand flats, and seagrass beds as feeding areas for juvenil fishes in Chwaka Bay, Zanzibar: Gut content and stable isotope analyses. Journal of Biology .69:1639-1661.

Lynch, Kevin. 1974. City Good Form. The MIT Press, Cambridge.

Supriharyono. 2000. Pelestarian dan Pengelolaan Sumberdaya Alam di Wilayah Pesisir Tropis. PT. Gramedia Pustaka Utama. Jakarta. 